\title{
Whole-grain dietary recommendations: the need for a unified global approach
}

\author{
Chris J. Seal ${ }^{1 *}$, Anne P. Nugent ${ }^{2}$, E-Siong Tee ${ }^{3}$ and Frank Thielecke ${ }^{4}$ \\ ${ }^{1}$ School of Agriculture, Food \& Rural Development, Human Nutrition Research Centre, Newcastle University, Newcastle upon \\ Tyne, NE1 7RU, UK \\ ${ }^{2} U C D$ Institute of Food and Health, UCD, Belfield, Dublin 4, Ireland \\ ${ }^{3}$ TES Nutrihealth Strategic Consultancy, 46 Jalan SS22/32, 47400 Petaling Jaya, Selangor D.E., Malaysia \\ ${ }^{4}$ Thielecke Consultancy, Bettenstrasse 60a, 4123 Allschwill, Switzerland
}

(Submitted 26 November 2015 - Final revision received 5 January 2016 - Accepted 1 March 2016 - First published online 15 April 2016)

\section{Abstract}

Increased whole-grain (WG) consumption reduces the risk of CVD, type 2 diabetes and some cancers, is related to reduced body weight and weight gain and is related to improved intestinal health. Definitions of 'WG' and 'WG food' are proposed and used in some countries but are not consistent. Many countries promote WG consumption, but the emphasis given and the messages used vary. We surveyed dietary recommendations of fifty-three countries for mentions of WG to assess the extent, rationale and diversity in emphasis and wording of any recommendations. If present, recommendations were classified as either 'primary', where the recommendation was specific for WG, or 'secondary', where recommendations were made in order to achieve another (primary) target, most often dietary fibre intake. In total, 127 organisations were screened, including government, non-governmental organisations, charities and professional bodies, the WHO and European Food Safety Authority, of which forty-nine including WHO provide a WG intake recommendation. Recommendations ranged from

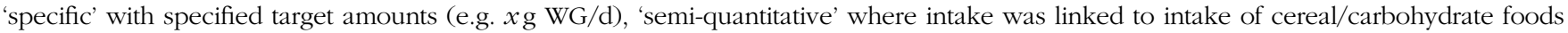
with proportions of WG suggested (e.g. $x$ servings of cereals of which $y$ servings should be WG) to 'non-specific' based on 'eating more' WG or 'choosing WG where possible'. This lack of a harmonised message may result in confusion for the consumer, lessen the impact of public health messages and pose barriers to trade in the food industry. A science-based consensus or expert opinion on WG recommendations is needed, with a global reach to guide public health decision making and increase WG consumption globally.

Key words: Whole grain: Whole-grain intakes: Dietary recommendations: Global recommendations

Cereals are the dominant source of carbohydrates in the diet worldwide and are significant contributors to protein intake in some countries where alternative crops and animal sources are not viable or are not consumed on religious grounds. Global cereal production approached 2525 million tonnes in 2014, of which wheat (28\%) and rice (20\%) accounted for approximately half of the total production ${ }^{(1)}$. Cereals require processing before consumption, either by cooking intact kernels or by milling and fractionation to produce flours. Since the development of the roller milling process, the tendency has been for the majority of cereals to be processed into (refined) flours by removing the outer layers of the kernel and the germ. As a result, consumption of whole grains and/or wholemeal flours has declined in many industrialised countries to the detriment of a more healthy diet pattern. Recent evidence points to the benefits of consuming whole grains, which are associated with lowered risk of several non-communicable diseases including type 2 diabetes, CVD and some cancers. However, in many countries, whole-grain intake is low despite efforts to promote their consumption by industry and government agencies. Reasons for low intake are complex but may include low consumer preference, lack of available products, cost difference between whole-grain and refined-grain products and lack of awareness of whole grains. Increasing intake of whole grains requires a concerted effort from health agencies and industry to standardise definitions of whole grains and whole-grain foods and to promote their consumption more effectively, including through national health initiatives.

\section{Composition of cereals}

Cereals are plants from the Gramineae family of grasses, and their seeds (grains) are characterised by their similarity in anatomical structure (see Fig. 1 for diagram of a wheat kernel), although not their overall chemical composition. Some

\footnotetext{
Abbreviations: EFSA, European Food Safety Authority; FBDG, food-based dietary guidelines.
} 


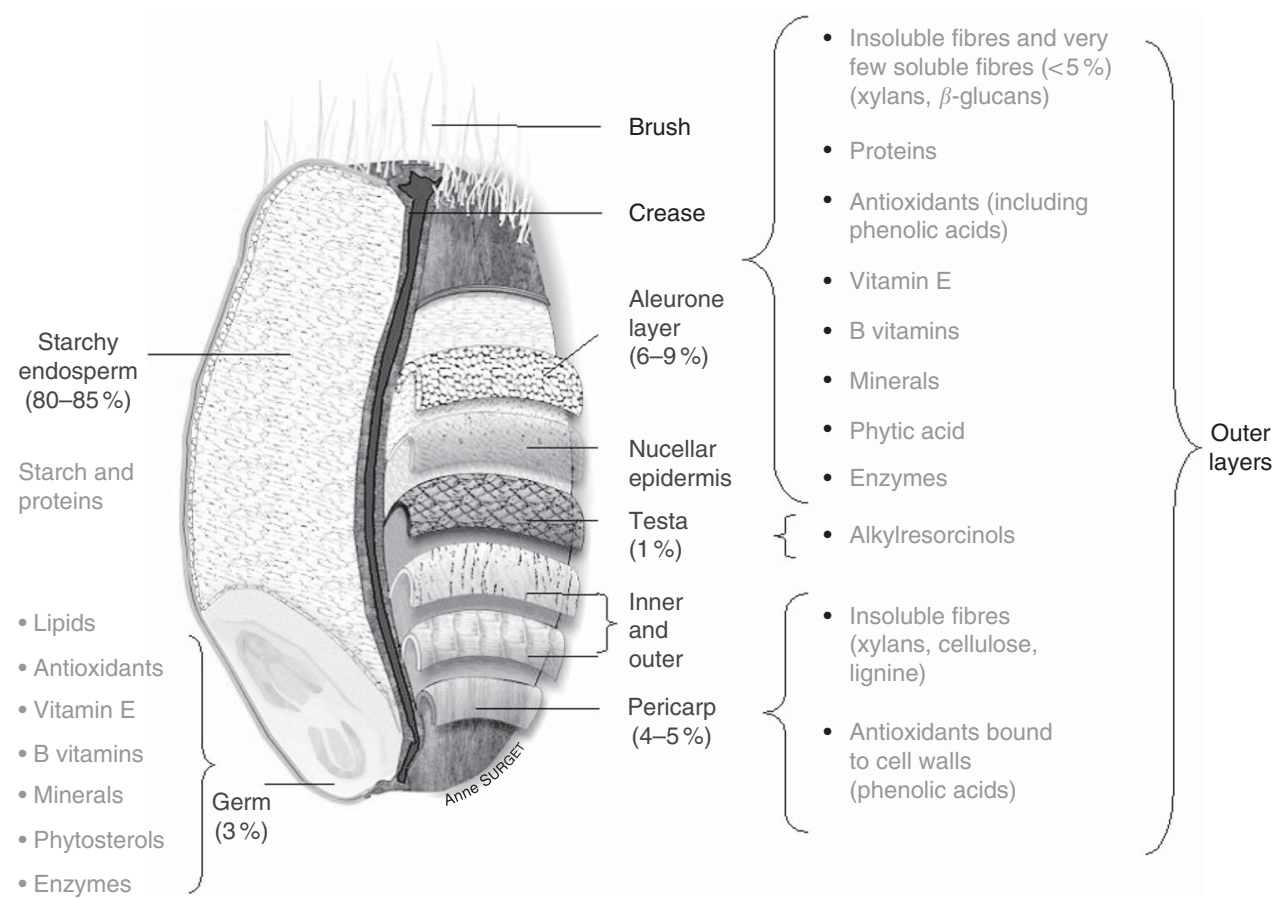

Fig. 1. Anatomical structure of a whole wheat $\operatorname{grain}^{(2,3)}$.

so-called pseudo-cereals are also included in the grain category because their structure is similar to true grains. Cereal grains have three principle anatomical components, each related to their function within the seed and each with unique composition, which affect the overall nutritional value of the different grain species. The bran is a multi-layered structure - the natural, tough protection of the seed beneath. There are several distinct layers including the pericarp and aleurone layers each of which are further sub-divided. These layers can be removed with great precision in modern milling methods; removal of each layer affects the nutrient profile of the fractions, especially dietary fibre(s), some vitamins and minerals and phytochemicals. The bran layers are also a principle source of phytochemicals and contribute to the antioxidant potential of grains. The biggest part of the grain is the endosperm, which comprises from about $60 \%$ up to almost $85 \%$ of the cereal grain dry weight, depending on the species. Nutritionally, the endosperm is mainly carbohydrate in the form of starches with smaller amounts of oligosaccharides such as fructans. Protein is found in the extracellular matrix, and there are some B vitamins, particularly pantothenic acid and riboflavin. The germ is the smallest fraction of the grain at about $2.5 \%$ of the grain weight. The germ is the growing part of the seed and it has high lipid and protein contents, with minerals such as $\mathrm{K}, \mathrm{Ca}, \mathrm{Mg}$ and $\mathrm{Zn}$, and both water- and fat-soluble vitamins including vitamin $\mathrm{A}$, tocopherols and tocotrienols.

\section{Definition of whole grain}

Various definitions of whole grain have been suggested, largely based on a definition proposed by the American Association of Cereal Chemists (AACC) International: 'whole grains consist of the intact, ground, cracked or flaked caryopsis (kernel) after the removal of inedible parts such as the hull and husk. The principal anatomical components - the starchy endosperm, germ and bran - are present in the same relative proportions as they exist in the intact kernel'. A similar definition has been proposed by the European HEALTHGRAIN Forum for adoption in the European Union $^{(4)}$. Each definition recognises that in modern milling processes the anatomical components of the grain are fractionated during milling but can be recombined to produce wholemeal flour, which contains all three components of the grain in the same relative proportions as in the intact grain. No distinction is made between the nutritional value of such recombined flours compared with traditional stone-ground flours where the grains are crushed without separation of the component fractions. The HEALTHGRAIN definition also recognises that some parts of the grain, especially the outermost layers, are deliberately removed during processing to cleanse potentially contaminated parts of the husk and outer bran. The Food and Drug Administration $(F D A)^{(5)}$ has issued draft guidelines for the food industry for use in identifying whole grains and in the use of different labelling terms to provide factual information on their products.

\section{Definition of whole-grain food}

There has been little consensus on a definition of 'whole-grain foods' both in terms of that used in scientific publications or within the food industry. Accurate labelling of whole-grain foods is needed to ensure that the consumer can properly differentiate between foods made entirely with whole grains, those where the majority of grains are whole (whole-grain rich) and foods that contain more refined grain than whole grain. The US FDA ${ }^{(6,7)}$ in its health claim definition has categorised a food 
product as being 'whole grain' if it contains more than 51\% whole-grain ingredients by weight/reference amount customarily consumed. The same criterion was applied by the Joint Health Claims Initiative in the $\mathrm{UK}^{(8)}$, but this is not a legal requirement. The Whole Grains Council provide a current list of definitions applied in different countries, including those used for their own Whole Grain Stamp ${ }^{(9)}$, which demonstrates the wide variation in standards. A recent round table of experts has proposed that $8 \mathrm{~g}$ of whole grain $/ 30 \mathrm{~g}$ serving $(27 \mathrm{~g} / 100 \mathrm{~g})$, without a fibre requirement, be considered a minimum content of whole grains that is nutritionally meaningful and that a food providing at least $8 \mathrm{~g}$ of whole grains $/ 30 \mathrm{~g}$ serving be defined as a whole-grain food ${ }^{(10)}$. Limitations in this proposed definition of a whole-grain food have been identified by the Whole Grains Council in its submission on whole-grain label statements to the FDA $^{(11)}$. Mostly these arise in foods that have high moisture content (such as bread products, ready-cooked pasta/grains and mixed ready meals) and foods that have a naturally low grain content but the portion size is $>30 \mathrm{~g}$. Refinement of the definition is therefore required so that naturally 'healthy' foods are not excluded from the category. The lack of clarity around a definition of what constitutes a whole-grain food confounds data analysis and comparison between studies. It is also not helpful for the food manufacturer or the consumer and gives rise to a number of different labelling approaches in ingredient lists and packaging stamps, which makes identifying healthy whole-grain options difficult ${ }^{(12)}$. The effect of using different definitions for whole-grain foods, for example, is well illustrated by analysis of data from the National Diet and Nutrition Surveys (NDNS) in the UK where the effect of using different cut-off values for whole-grain content was examined ${ }^{(13,14)}$. Overall, in young people under 19 years of age, foods with $\geq 51 \%$ wholegrain content contributed $72 \%(95 \%$ CI 70,74$)$ to whole-grain intake. Foods with between 25 and $51 \%$ whole grain contributed $13 \%(95 \%$ CI 11,15$)$ to whole-grain intake, with the remainder being contributed by those containing between 10 and $25 \%$ whole grain ${ }^{(13)}$. In the analysis of the secular trend in whole-grain intake in adults, Thane et al. ${ }^{(14)}$ again showed that foods with $<51 \%$ whole-grain content are important contributors to whole-grain intake, providing $18 \%$ of overall whole-grain intake in the 1986-1987 survey and $27 \%$ in the 2000-2001 survey. If a cut-off point of $25 \%$ rather than $10 \%$ whole-grain content was used, whole-grain intake would have been underestimated by $6 \%$ in 1986-1987 and by $10 \%$ in 2000-2001. Choosing an appropriate cut-off value also has important implications for public health and industry. There is an understandable concern that defining products with $<25 \%$ whole grain as whole-grain foods may include foods with undesirable nutrient profiles, which would be detrimental to population health. There are obvious consequences for recommendations for whole-grain intake.

\section{Whole-grain intake levels}

Consumption of whole grain varies greatly between countries and cultures, with some countries maintaining a more traditional dietary pattern in which whole-grain foods dominate compared with more recent processed refined-grain alternatives. Determining whole-grain intake in populations has been problematic for a number of reasons: (1) in many studies, whole-grain intake has been determined more than 25 years ago when the number of whole-grain foods available for purchase was much lower than at present; (2) the majority of data on whole-grain intake has traditionally been derived from North American population-based studies, which may not be nationally representative in which food intake is calculated from FFQ mostly not originally designed for this purpose; (3) the number and descriptor of the foods included in FFQ is limited; (4) the percentage of whole grain content used to define the wholegrain foods included in analyses varies between 10 and 51\%; (5) there is no standardisation of portion/serving sizes used when calculating intake; and (6) in many countries there is no standard list of the actual whole-grain content of the majority of foods as this is not a standard component of food tables. Data on foods in the USA are now publicly available through the US Department of Agriculture Food (USDA) Patterns Equivalents Database $^{(15)}$, and recently the whole grain content of foods in Australia has been published ${ }^{(16)}$. No similar databases are currently available for European or Asian populations. On balance, it is likely that whole-grain intake is probably higher than that originally reported, and this needs to be re-investigated.

Available studies, however, universally reveal low levels of consumption in North Americans and most Europeans (Table 1). Much of the data are quite old, and the availability and range of whole-grain foods in the marketplace have changed considerably in recent years. Overall, however, the results suggest that whole-grain intake has not changed much over time, except where specific public health campaigns have taken place, such as in Denmark ${ }^{(40)}$. The majority of published data are reported at a population level, that is, they are median/ mean values for the whole population including consumers and non-consumers in the calculations. Intake data from observational studies may be reported by quartiles or quintiles of intake adding to the complexity of comparison with population data. In some of the first results published, $<20 \%$ of the 38740 postmenopausal women participating in the Iowa Women's Health Study consumed three or more servings of whole-grain foods per day ${ }^{(24)}$. Similar consumption levels were reported in another American cohort of 38-63-year-old females in the Nurses' Health Study ${ }^{(25)}$. Analysing food consumption data from the Market Research Corporation of America, Albertson \& Tobelmann $^{(26)}$ found that $90 \%$ of those under 19 years of age and $73 \%$ of those aged over 19 years reported less than one whole-grain eating occasion per day. In the UK, more recent data (but also more than 15 years old) from the NDNS showed that median whole-grain intake was less than one serving per day, over $97 \%$ of adults and young people under 18 years of age did not achieve $48 \mathrm{~g} / \mathrm{d}$ and $>30 \%$ of individuals consumed no whole grains at all ${ }^{(13,14)}$. The most up-to-date data for the UK, from the first 3 years of the NDNS Rolling Programme for 2008/2009-2010-2011, show that, although intake has increased slightly since 2001, intake remains low, and $20 \%$ of the population still consume no whole grains ${ }^{(19)}$. Similar low intake levels were found for those over 65 years of age by Lang et $a l .{ }^{(27)}$, and in older women from the Iowa Women's Health 
Table 1. Whole-grain intake in different populations

(Medians and 5th, 95th percentiles; mean values with their standard errors)

\begin{tabular}{|c|c|c|c|c|c|c|c|c|}
\hline \multirow[b]{2}{*}{ Countries } & \multirow[b]{2}{*}{$\operatorname{Sex}(n)$} & \multicolumn{2}{|c|}{ Age group (years) } & \multicolumn{2}{|c|}{ Mean intake $(g / d)$} & \multicolumn{2}{|c|}{ Median intake $(\mathrm{g} / \mathrm{d})$} & \multirow[b]{2}{*}{ Source (year data collected) } \\
\hline & & Median & 5th, 95th percentile & Mean & SE & Median & 5th, 95th percentile & \\
\hline Norway & $F(1797)$ & 48 & 42,55 & 51 & 36 & 44 & 0,120 & ${ }^{(17)}(1995-2000)$ \\
\hline \multirow[t]{2}{*}{ Sweden } & $F(1617)$ & 50 & 40,60 & 41 & 32 & 35 & 0,120 & \\
\hline & $M(1372)$ & 60 & 40,60 & 58 & 50 & 49 & 0,149 & \\
\hline \multirow[t]{2}{*}{ Denmark } & F (1994) & 56 & 51,64 & 37 & 32 & 31 & 0,92 & \\
\hline & M (1922) & 56 & $51,64^{*}$ & 48 & 42 & 41 & $0,116^{*}$ & \\
\hline \multirow[t]{2}{*}{ France } & Both (1171) & $3-17$ & & 4 & 0.3 & 0 & $20 \cdot 5^{\star}$ & ${ }^{(18)}(2010)$ \\
\hline & Both (1389) & $>18$ & & 5 & 0.3 & 0 & $26 \cdot 4^{*}$ & \\
\hline \multirow{4}{*}{ UK } & $F(729)$ & $1.5-17$ & & $15 \cdot 3$ & $15 \cdot 0$ & 11 & 4,42 & (19) $(2008-2011)$ \\
\hline & M (773) & $1.5-17$ & & $20 \cdot 1$ & 20.4 & 15 & 5,29 & \\
\hline & $F(880)$ & $>18$ & & $23 \cdot 6$ & $22 \cdot 8$ & 19 & 6,35 & \\
\hline & M (691) & $>18$ & & 28.9 & 31.1 & 20 & 3,42 & \\
\hline \multirow[t]{4}{*}{ Germany } & $F(275)$ & $6-12$ & & 22 & 22.9 & $14 \cdot 7$ & $0,57 \dagger$ & (20)(1997-2008) \\
\hline & $M(280)$ & $6-12$ & & 27 & 29.5 & 17.9 & $0,66 \dagger$ & \\
\hline & $\mathrm{F}(165)$ & $13-18$ & & 24 & 28.7 & $16 \cdot 3$ & $0,56 \dagger$ & \\
\hline & M (170) & $13-18$ & & 33 & 43.7 & 19.2 & $0,84 t$ & \\
\hline \multirow[t]{3}{*}{ Ireland } & Both (594) & $5-12$ & & 18.5 & $18 \cdot 2$ & $12 \cdot 7$ & $68 \cdot 5 \ddagger$ & ${ }^{(21)}(2003-2006) \S$ \\
\hline & Both (441) & $13-17$ & & $23 \cdot 2$ & 29.5 & $13 \cdot 4$ & $97.9 \ddagger$ & \\
\hline & Both (1051) & $18-90$ & & $36 \cdot 3$ & 34.0 & 29.0 & $118.9 \ddagger$ & (22) $(2008-2010)$ \\
\hline \multirow[t]{2}{*}{ USA } & Both (3124) & $2-18$ & & $16 \cdot 2$ & 0.57 & & & (23) $(2009-2010)$ \\
\hline & Both (5918) & $\geq 19$ & & $23 \cdot 2$ & 0.85 & & & \\
\hline
\end{tabular}

* Medians and 95th percentiles.

† Medians and 10th, 90th percentiles.

$\ddagger 50$ th and 97.5 th percentiles.

$\S 2003-2004$ for age 5-12 years; 2005-2006 for age 13-17 years.

Study the mean intake was again lower, ranging from 1.8 ( $\mathrm{SD} 1 \cdot 1$ ) serves/week in the lowest quintile to 25.7 (SD 7.5) serves/week in the highest quintile.

Whole-grain intake in Northern European countries is higher than in most other countries, particularly other European nations and the American continent. Whole-grain food and whole-grain intake estimates across the Scandinavian countries have recently been reported by Kyro et $a l .{ }^{(17)}$. The study population of 8702 adults was from the HELGA cohort study on 'Nordic health and whole-grain food' randomly selected as a subset from the three prospective Scandinavian cohort studies: the Norwegian Women and Cancer Cohort, the Northern Sweden Health and Disease Cohort and the Danish Diet Cancer and Health Cohort. Wholegrain intake was determined from a comprehensive 24-h dietary recall using European Prospective Investigation into Cancer and Nutrition-soft software, which includes country-specific food and recipe lists with traditional foods and dishes ${ }^{(28)}$. Further Danish data from Egeberg et $a l .{ }^{(29)}$ based on the total weight of foods containing whole grains show similar high intakes of whole-grain foods for adults at 140 (95\% CI 48, 279) and 119 (95\% CI 40, 237) g whole-grain foods/d for men and women, respectively. There is a dearth of published data on consumption of whole grains in the Asian region. Data from the National Nutrition Survey of Singapore in $2010^{(30)}$ and a recent study in Malaysian children and adolescents $^{(31)}$ suggest that whole-grain intake in this region is low.

\section{Whole-grain health claims}

The health benefits of whole grain were recognised by some National organisations through the development of health claims permitted for use on whole-grain foods. The first, established by the US FDA in 1999, was modified in 2003 and states 'Diets rich in whole-grain foods and other plant foods, and low in saturated fat and cholesterol, may help reduce the risk of heart disease ${ }^{\text {(7); }}$; the claim is still in use. In Europe, similar claims previously in use in the UK and Sweden are no longer allowed following the decision by the European Food Safety Authority (EFSA) not to approve a whole-grain health claim on the grounds that whole grain was insufficiently characterised"(32). A particular issue in this context is the use of the term 'whole grain' to encompass all the grains; applications for health claims were not specific to individual grains (i.e. whole-grain wheat or whole-grain rye). This is similar to the use of 'fruit and vegetables', where dietary recommendations are for the most part based on the whole food group with a few countries specifying relative amounts of fruits and vegetables, and none specifying specific amounts of individual fruits or vegetables. In Southeast Asia, only Singapore permits the use of a health claim relating whole grains and reduction of risk of heart disease and some types of cancers ${ }^{(33)}$.

\section{Food-based dietary guidelines}

Most countries have developed food-based dietary guidelines (FBDG) appropriate for their population, recognising that these have become an accepted tool for promoting appropriate dietary patterns. These guidelines are often a set of positive messages that cover the whole range of food and nutrition issues, from importance of consuming a variety of foods to guidance on specific food groups, messages to encourage physical activities, consuming safe food and beverages and 
Table 2. Countries surveyed and sources identified

\begin{tabular}{|c|c|c|c|c|c|c|c|}
\hline \multirow[b]{3}{*}{ Regions } & \multirow{3}{*}{$\begin{array}{c}\text { Countries } \\
\text { searched }(n)\end{array}$} & \multicolumn{2}{|c|}{ Organisations screened $(n)$} & \multirow{2}{*}{\multicolumn{4}{|c|}{ Recommendation }} \\
\hline & & \multirow{2}{*}{$\begin{array}{l}\text { Government } \\
\text { authority }\end{array}$} & \multirow{2}{*}{$\begin{array}{c}\mathrm{NGO} / \text { charity/ } \\
\text { professional body }\end{array}$} & & & & \\
\hline & & & & Yes & No & Primary & Secondary \\
\hline Australia and New Zealand & 2 & 2 & 2 & 4 & 0 & 1 & 3 \\
\hline Asia & 10 & 5 & 18 & 4 & 14 & 1 & 3 \\
\hline Europe & 19 & 11 & 51 & 22 & 16 & 6 & 16 \\
\hline Africa and South Africa & 2 & 2 & 2 & 3 & 1 & 3 & 0 \\
\hline North America & 2 & 2 & 7 & 9 & 0 & 5 & 4 \\
\hline Latin America & 9 & 6 & 5 & 4 & 7 & 0 & 4 \\
\hline Middle East & 9 & 9 & 3 & 2 & 2 & 1 & 1 \\
\hline WHO & N/A & 0 & 1 & 1 & 0 & 1 & 0 \\
\hline EFSA & $\mathrm{N} / \mathrm{A}$ & 0 & 1 & 0 & 1 & $\mathrm{~N} / \mathrm{A}$ & $\mathrm{N} / \mathrm{A}$ \\
\hline Total & 53 & 37 & 90 & 49 & 41 & 18 & 31 \\
\hline
\end{tabular}

NGO, non-governmental organisation; EFSA, European Food Safety Authority

making effective use of nutrition information on food labels. The topics included in national FBDG and approaches to presentation of these messages differ widely across the countries.

Dietary recommendations in most countries are developed by expert panels and disseminated through national health agencies and can be based on nutrients and/or foods. EFSA have proposed a framework for the development of FBDG appropriate for whole grains based on the following principles ${ }^{(34)}$ :

1. identification of diet-health relationships;

2. identification of country-specific, diet-related health problems;

3. identification of nutrients of public health importance;

4. identification of foods relevant for FBDG;

5. identification of food consumption patterns;

6. testing and optimising FBDG;

7. graphical representations of FBDG; and

8. FBDG should focus on diet-disease relationships of particular relevance to the specific population and should be developed using a multidisciplinary approach.

FBDG should be policy recommendations based on the best available scientific evidence; the principles suggested by EFSA imply that they should be appropriate for the region or country for which they are intended and, importantly, they should be practical to implement. EFSA state that they should be consistent, easily understood and easily memorisable.

\section{Current whole-grain dietary recommendations}

Many dietary guidelines have recommendations for specific food items - for example, cereal-based products, fruits and vegetables, milk and dairy products, and legumes. Less frequently wholegrains are included, but the extent to which they occur is unknown. Therefore, we conducted a survey of current wholegrain dietary recommendations, reviewing websites and personal communication with national governmental and professional health agencies/organisations using a network of nutritionists available to us. Recommendations, if present, were initially classified into two categories: (a) primary, where the recommendation was specific for whole grains and (b) secondary, where the recommendation was made in order to achieve another (primary) target, most often dietary fibre intake. The rationale behind any recommendations was noted where this information was provided. In all, fifty-three countries plus the WHO and EFSA were surveyed and results were obtained from 127 separate organisations, including national competent authorities, non-governmental organisations (NGO), charities and professional bodies, the WHO and EFSA (Table 2). Recommendations were variable and inconsistent and fell into three categories as shown in Table 3: specific recommendations where a target daily amount was specified; semi-quantitative recommendations where a recommendation was based on servings of cereal foods with proportions of whole grain suggested; and non-specific recommendations based on 'eating more' or 'choosing' whole-grain options. Specific recommendations adopted by government agencies, including target intake amounts, were found for only two countries (USA and Denmark). For some countries, different recommendations were found for NGO, charities or professional bodies but not for government - for example, in Australia the Grains and Legumes Nutrition Council $^{(35)}$ suggests a whole-grain daily target intake of $48 \mathrm{~g}$ whole grain/d for adults and children aged 9 years and above, but the Australian Government Department of Health and Ageing Dietary Guidelines for Australians has only a generic recommendation 'eat plenty of cereals (including breads, rice, pasta and noodles), preferably whole grain'. This inconsistency in approach largely arises from the rationale given for the recommendations, which are mostly associated with setting targets for dietary fibre intake and promoting whole grains as rich sources of dietary fibre, rather than being based on the health benefits of consuming whole grains per se. Thus, a gap exists between the scientific consensus that whole grains are beneficial to health and public health policies designed to promote healthy eating. A full list of the available recommendations can be found in the online Supplementary material.

\section{Development of global whole-grain intake recommendations}

Grain foods are universally recognised by government health agencies as the cornerstone of dietary recommendations alongside other carbohydrate-rich sources, and are promoted as essential providers of dietary energy and other essential nutrients 
including dietary fibre. Thus, they are often found in the base of food pyramids or in the largest segment of plate models used to illustrate food-based dietary recommendations to the general population. In these systems, no distinction is made between cereal types and whole grains are not generally specified. The Harvard Healthy Eating Pyramid ${ }^{(36)}$ suggests the consumption of whole-grain foods (at most meals) and the Iberoamerican Nutrition Foundation has recently proposed a three-dimensional food and lifestyle pyramid, which has 'cereal and cereal products $>50 \%$ whole grain' as the second tier of the pyramid, also acknowledging the importance of this food category ${ }^{(37)}$. Food guides are broadly similar in their overall approach to promote a diet based on eating more fruits, vegetables, legumes and whole grains, eating less added sugar and SFA, and using plant oils. Comparison between different food guides including the USDA's MyPyramid and the Harvard Healthy Eating Pyramid showed that nutrient intakes derived from the guides were similar despite the different foods suggested in each plan ${ }^{(38)}$.

In addition to being a key source of energy, protein, micronutrients and phytochemicals to the diet, whole-grain cereals are an important source of different dietary fibres. Increased consumption of whole grains improves the overall quality of the diet and in particular is a good way to increase dietary fibre intake, which in many countries is lower than the recommendations. The fact that fibre consumption remains low, in parallel with low intake of whole grains in most countries, suggests that this approach has not been successful and new strategies are needed to improve this deficit ${ }^{(39)}$. As an example, the Danish dietary recommendation is based on modelling of dietary intake, assuming that targets for fruit and vegetable consumption are achieved and that the additional dietary fibre should come from other food sources including whole-grain foods. Whole-grain intake in Denmark has increased markedly by $72 \%$ from a population average of $32 \mathrm{~g} / \mathrm{d}$ in 2000-2004 to $55 \mathrm{~g} / \mathrm{d}$ in 2011-2012 $2^{(40)}$ following the successful Danish national campaign to promote whole-grain intake. The proportion of Danes meeting the Danish target of $75 \mathrm{~g} / 10 \mathrm{MJ}$ rose from 6 to $27 \%$ of the population, demonstrating that a well-designed public health campaign in support of a specific dietary recommendation can be effective in promoting dietary change.

Within the scientific community, there is broad consensus on the health benefits of consuming whole grains, but this has not been translated into consistent health messages and dietary recommendations. The wide range of dietary recommendations found in this investigation and the lack of recommendations in many countries should be addressed; where possible, countries without whole-grain intake recommendations should be encouraged to incorporate them into dietary guidelines. In our opinion, this is best achieved through the development of a science-based consensus or expert opinion on whole-grain intake recommendations with a global reach. Such an expert opinion should consider the totality of available scientific evidence to address the following:

- whether a global standard definition for whole grains and whole-grain food can be adopted;

- whether a global whole-grain intake recommendation is possible; 
- whether a whole-grain intake recommendation should be generic, or whether a recommendation should be based on a specific grain type, for example, whole-grain wheat or whole-grain rye; and

- whether a whole-grain intake recommendation should be quantitative or generic, for example, 'consume $\times$ grams of whole grain' or 'eat more whole grains'.

The purpose of the developed recommendation would be to guide health policies and raise consumer awareness of whole grains in order to change peoples' diets to derive a greater proportion of dietary energy from cereal foods, which provide dietary fibre and associated micronutrients and phytochemicals that are lost in the refining process. A greater harmonisation in approach would not only aid health professionals develop strategies to increase whole-grain consumption but also would encourage and enable food manufacturers to develop healthy and affordable products containing whole grains.

\section{Acknowledgements}

No funding was received for the writing of the commentary.

F. T. was an employee of Cereal Partners Worldwide and Nestlé when this work was initiated, global manufacturers of cereal-based products. C. J. S. is currently in receipt of unrestricted research funding from Cereal Partners Worldwide; A. P. N. and E.-S. T. have previously received unrestricted research funding from Cereal Partners Worldwide. C. J. S., A. P. N. and F. T. are members of the HEALTHGRAIN Forum, a not-for-profit Association bounded by the Finnish Associations Act No. 503 of 26 May 1989, pursuing a networking and scientific aim to promote and develop grain and grain products.

The commentary represents solely the views of the authors who declare no conflicts of interest.

\section{Supplementary material}

For supplementary material/s referred to in this article, please visit http://dx.doi.org/doi:10.1017/S0007114516001161

\section{References}

1. Food and Agriculture Organization of the United Nations (2015) FAO cereal supply and demand brief, 4 June. http:// www.fao.org/worldfoodsituation/csdb/en/ (accessed June 2015).

2. Hemery Y, Rouau X, Lullien-Pellerin V, et al. (2007) Dry processes to develop wheat fractions and products with enhanced nutritional quality. J Cereal Sci 46, 327-347.

3. Surget A \& Barron C (2005) Histologie du grain de blé (Histology of wheat grain). Industrie des Céréales 145, 3-7.

4. van der Kamp JW, Poutanen K, Seal CJ, et al. (2014) The HEALTHGRAIN definition of 'whole grain'. Food Nutr Res $\mathbf{5 8}$ 10.3402/fnr.v58.22100.

5. Food and Drug Administration (FDA) (2006) Guidance for Industry and FDA Staff. Whole Grain Label Statements. Draft Guidance. http://www.fda.gov/Food/GuidanceCompliance RegulatoryInformation/GuidanceDocuments/FoodLabeling Nutrition/ucm059088.htm (accessed January 2013).
6. Food and Drug Administration (FDA) (1999) Health claim notification for whole grain foods. http://www.fda.gov/Food/ IngredientsPackagingLabeling/LabelingNutrition/ucm073639. htm (accessed April 2015).

7. Food and Drug Administration (FDA) (2003) Health claim notification for whole grain foods with moderate fat content. http://www.fda.gov/Food/IngredientsPackagingLabeling/ LabelingNutrition/ucm073634.htm (accessed January 2013).

8. Joint Health Claims Initiative (2002) Generic health claim for wholegrain foods and heart health. http://www.jhci.org.uk/ approv/wgrainh.htm (accessed January, July 2013).

9. Whole Grains Council (2015) Existing standards for whole grains. http://wholegrainscouncil.org/whole-grains-101/existingstandards-for-whole-grains (accessed July 2015).

10. Ferruzzi MG, Jonnalagadda SS, Liu S, et al. (2014) Developing a standard definition of whole-grain foods for dietary recommendations: summary report of a multidisciplinary expert roundtable discussion. Adv Nutr 5, 164-176.

11. Whole Grains Council (2015) Letter to FDA Re: Draft Guidance for Industry and FDA Staff@ Whole Grain Label Statements, Docket No. FDA-2006-D-0298-001 (formerly 2006D-0066). http://wholegrainscouncil.org/files/WGCtoFDA Jan2014.pdf (accessed July 2015).

12. Mozaffarian RS, Lee RM, Kennedy MA, et al. (2013) Identifying whole grain foods: a comparison of different approaches for selecting more healthful whole grain products. Public Health Nutr 16, 2255-2264

13. Thane CW, Jones AR, Stephen AM, et al. (2005) Whole-grain intake of British young people aged 4-18 years. Br J Nutr $\mathbf{9 4}$, $825-831$.

14. Thane CW, Jones AR, Stephen AM, et al. (2007) Comparative whole-grain intake of British adults in 1986-7 and 2000-1. Br J Nutr 97, 987-992.

15. US Department of Agriculture (2015) Food Patterns Equivalents Database 2011-2012. http://www.ars.usda.gov/SP2UserFiles/ Place?80400530/pdf/fped/FPED_2011_2012_Fact_Sheet.pdf (accessed July 2015).

16. Dalton SMC, Probst YC, Batterham MJ, et al. (2014) Compilation of an Australian database of manufactured and packaged food products containing wholegrain ingredients. J Food Compost Anal 36, 24-34.

17. Kyro C, Skeie G, Dragsted LO, et al. (2012) Intake of whole grain in Scandinavia: intake, sources and compliance with new national recommendations. Scand J Public Health 40, 76-84.

18. Bellisle F, Hébel P, Colin J, et al. (2014) Consumption of whole grains in French children, adolescents and adults. $\mathrm{BrJ}$ Nutr 112, 1674-1684.

19. Mann KD, Pearce MS, McKevith B, et al. (2015) Low whole grain intake in the UK: results from the National Diet and Nutrition Survey rolling programme 2008-2011. Br J Nutr $\mathbf{1 1 3}$, $1643-1651$

20. Alexy U, Zorn C \& Kersting M (2010) Whole grain in children's diet: intake, food sources and trends. Eur J Clin Nutr 64 745-751.

21. Devlin NFC, McNulty BA, Gibney MJ, et al. (2013) Whole grain intakes in the diets of Irish children and teenagers. Br J Nutr 110, 354-362.

22. Devlin NFC, McNulty BA, Walton J, et al. (2015) Whole grain intake and nutrient health in Irish adults. Proc Nutr Soc 74 (OCE4), E63

23. Reicks M, Jonnalagadda S, Albertson AM, et al. (2014) Total dietary fiber intakes in the US population are related to whole grain consumption: results from the National Health and Nutrition Examination Survey 2009 to 2010. Nutr Res 34, 226-234 
24. Jacobs DR, Meyer KA, Kushi LH, et al. (1999) Is whole grain intake associated with reduced total and cause-specific death rates in older women? The Iowa Women's Health Study. Am J Public Health 89, 322-329.

25. Liu S, Stampfer MJ, Hu FB, et al. (1999) Whole-grain consumption and risk of coronary heart disease: results from the Nurses' Health Study. Am J Clin Nutr $\mathbf{7 0}$, 412-419.

26. Albertson AM \& Tobelmann RC (1995) Consumption of grain and whole-grain foods by an American population during the years 1990 to 1992. J Am Diet Assoc 95, 703-704.

27. Lang R, Thane CW, Bolton-Smith C, et al. (2003) Consumption of whole grain foods by British adults: findings from further analysis of two national dietary surveys. Public Health Nutr $\mathbf{6}$, 479-484.

28. Slimani N, Ferrari P, Ocke M, et al. (2000) Standardization of the 24-hour diet recall calibration method used in the European Prospective Investigation into Cancer and Nutrition (EPIC): general concepts and preliminary results. Eur J Clin Nutr 54, 900-917.

29. Egeberg R, Frederiksen K, Olsen A, et al. (2009) Intake of wholegrain products is associated with dietary, lifestyle, anthropometric and socio-economic factors in Denmark. Public Health Nutr 12, 1519-1530.

30. Health Promotion Board Singapore (2010) Report of the National Nutrition Survey 2010. Singapore: Health Promotion Board Singapore.

31. Norimah A, Koo HC, Hamid JJ, et al. (2015) Whole grain intakes in the diets of Malaysian children and adolescents findings from the MyBreakfast Study. PLOS ONE 10, $\mathrm{e} 0138247$.

32. European Food Safety Authority (2010) Scientific opinion on the substantiation of health claims related to whole grain (ID
$831,832,833,1126,1268,1269,1270,1271,1431)$ pursuant to Article 13(1) of Regulation (EC) No 1924/2006. EFSA J 8, 1766.

33. Tee E (2014) Regulatory framework of functional foods in Southeast Asia. In Clinical Aspects of Functional Foods and Nutraceuticals, pp. 197-216 [D Ghosh, D Baghchi and T Konishi, editors]. Boca Raton, FL: CRC Press.

34. European Food Safety Authority (2010) Scientific opinion on establishing food-based dietary guidelines. EFSA J 8, 1460.

35. Grains and Legumes Nutrition Council (2014) Whole grain foods - a hallmark of a healthy diet. http://www.glnc.org.au/ (accessed July 2014).

36. Willett WC (2005) Eat, Drink, and Be Healthy: The Harvard Medical School Guide to Healthy Eating. New York, NY: Simon and Schuster.

37. Gil A, Ruiz-Lopez MD, Fernandez-Gonzalez M, et al. (2014) The FINUT healthy lifestyles guide: beyond the food pyramid. Adv Nutr 5, 358S-367S.

38. Reedy J \& Krebs-Smith SM (2008) A comparison of food-based recommendations and nutrient values of three food guides: USDA's MyPyramid, NHLBI's Dietary Approaches to Stop Hypertension Eating Plan, and Harvard's Healthy Eating Pyramid. J Am Diet Assoc 108, 522-528.

39. Mobley AR, Slavin JL \& Hornick BA (2013) The future of recommendations on grain foods in dietary guidance. $J$ Nutr 143, 1527S-1532S.

40. Mejborn H, Ygil K, Fagt S, et al. (2013) Danskernes fuldkornsindtag 2011-2012, E-artikel fra DTU Fødevareinstitutet No. 2 (Danish whole grain intake 2011-2012, E-article from the National Food Institute No. 2). http://www.food.dtu.dk/english/ /media/Institutter/Foedevareinstituttet/Publikationer/Pub2013/Rapport_Fuldkornsindtag_11-12_UK.ashx (accessed August 2014). 